\title{
Active Flow Control (AFC) and Insect Accretion and Mitigation (IAM) System Design and Integration on the Boeing 757 ecoDemonstrator
}

\author{
Michael G. Alexander ${ }^{*}$, F. Keith Harris ${ }^{\dagger}$ \\ NASA Langley Research Center, Hampton, VA, 23681, USA
}

Marc A. Spoor ${ }^{\ddagger}$, Susannah R. Boyland ${ }^{\S}$, Thomas E. Farrell ${ }^{* *}$

The Boeing Company, Boeing Commercial Airplanes, Seattle, WA, 98124, USA

David M. Raines ${ }^{\dagger \dagger}$

Boeing Defense \& Space, Huntsville Design Center, Huntsville, AL, 35802, USA

* Aerospace Engineer, System Engineering and Engineering Methods Branch, MS D209

${ }^{\dagger}$ Program Specialist, Aerospace System Engineering Branch, MS238

${ }^{\ddagger}$ Engineer, Boeing Commercial Airplanes, Technology Integration, Mail Stop: OR-104

$\S$ Engineer, Boeing Commercial Airplanes, Systems Engineering, Mail Stop: 03-AA

** Engineer, Boeing Commercial Airplanes, Aerodynamics Engineering, Mail Stop: OR-120

${ }^{\dagger+}$ Engineer, Boeing Defense, Space \& Security, Huntsville Design Center, Mail Stop: JN-65 


\begin{abstract}
This paper presents a systems overview of how the Boeing and NASA team designed, analyzed, fabricated, and integrated the Active Flow Control (AFC) technology and Insect Accretion Mitigation (IAM) systems on the Boeing 757 ecoDemonstrator. The NASA Environmentally Responsible Aviation (ERA) project partnered with Boeing to demonstrate these two technology systems on a specially outfitted Boeing 757 ecoDemonstrator during the spring of 2015. The AFC system demonstrated attenuation of flow separation on a highly deflected rudder and increased the side force generated. This AFC system may enable a smaller vertical tail to provide the control authority needed in the event of an engine failure during takeoff while still operating in a conventional manner over the rest of the flight envelope. The AFC system consisted of ducting to obtain air from the Auxiliary Power Unit (APU), a control valve to modulate the system mass flow, a heat exchanger to lower the APU air temperature, and additional ducting to deliver the air to the AFC actuators located on the vertical tail. The IAM system demonstrated how to mitigate insect residue adhesion on a wing's leading edge. Something as small as insect residue on a leading edge can cause turbulent wedges that interrupt laminar flow, resulting in an increase in drag and fuel use. The IAM system consisted of NASA developed Engineered Surfaces (ES) which were thin aluminum sheet substrate panels with coatings applied to the exterior. These ES were installed on slats 8 and 9 on the right wing of the 757 ecoDemonstrator. They were designed to support panel removal and installation in one crew shift. Each slat accommodated 4 panels. Both the AFC and IAM flight test were the culmination of several years of development and produced valuable data for the advancement of modern aircraft designs.
\end{abstract}

\title{
Nomenclature
}

$\begin{array}{lll}\text { ADAMS } & = & \text { Airborne Data Analysis/Monitoring System } \\ \text { AFC } & = & \text { Active Flow Control } \\ \text { APU } & = & \text { Auxiliary Power Unit } \\ \text { BART } & = & \text { Basic Aerodynamic Research Tunnel } \\ \text { CFD } & = & \text { Computational Fluid Dynamics } \\ \text { ECS } & = & \text { Environmental Control Systems } \\ \text { EMI } & = & \text { Electromagnetic Interference } \\ \text { ERA } & = & \text { Environmentally Responsible Aviation } \\ \text { ES } & = & \text { Engineered Surfaces } \\ \text { GUI } & = & \text { Graphical User Interface } \\ \text { HT } & = & \text { High Temperature } \\ \text { HX } & = & \text { Heat Exchanger } \\ \text { LaRC } & = & \text { Langley Research Center } \\ \text { NASA } & = & \text { National Aeronautics and Space Administration } \\ \text { NFAC } & = & \text { National Full-Scale Aerodynamics Complex } \\ \text { TRL } & = & \text { Technology Readiness Level } \\ \text { UV } & = & \text { Ultraviolet }\end{array}$

\section{Introduction}

$\mathrm{T}$ HE NASA Environmentally Responsible Aviation (ERA) project's main purpose was to mature technologies focused on simultaneously reducing fuel consumption, nitrogen oxides from emissions, and community noise profiles of modern passenger and cargo transport aircraft. ${ }^{1,2}$ Aircraft drag reduction is a continuing top priority for commercial, military, and general aviation. Skin friction (or viscous drag) contributes approximately $50 \%$ of the total drag of a transport aircraft, ${ }^{3,4}$ and its reduction has the potential to achieve a substantial decrease in fuel burn. Indirect benefits of the aircraft drag reduction (or lower fuel consumption) include increased range, the capability to transport heavier payloads, and lower engine emissions. The ERA project was interested in innovative approaches for aircraft drag reduction. It sponsored a number of technology maturation efforts from 2010 to 2015 that were targeted at improving aircraft fuel efficiencies. Research was conducted to mature selected technologies from NASA 
technology readiness levels (TRL) ranging from 3 to 6 with emphases on those technologies that could be matured to a higher readiness level and have demonstrated commercial viability in the 2020 to 2025 timeframe.

Two drag reduction technologies, AFC and IAM, were chosen by ERA for technology maturation that culminated in a flight demonstration on the Boeing 757 ecoDemonstrator aircraft. The first drag reduction technology employed an array of pneumatic-based AFC devices called the sweeping jet actuators ${ }^{5}$ (Figure 1) on the vertical tail of the Boeing 757 for side force enhancement (Figure 2) ${ }^{6}$ These devices were of the same geometry and configuration that was successfully tested on a full-scale Boeing 757 vertical tail model in NASA Ames' National Full-Scale Aerodynamics Complex (NFAC) 40'x80' wind tunnel. ${ }^{7,8}$ A NASA sponsored system integration study on a mid-sized twin aisle airplane indicated using AFC would allow designers to scale-down the vertical tail of a mid-sized twin aisle airplane and reduce aircraft drag by $0.4 \%$, which would reduce fuel burn. ${ }^{9}$ The second drag reduction technology, IAM, involved the use of an engineered surface (ES) with non-stick coatings. ${ }^{10}$ These coatings could mitigate insect residue adhesion on a wing's leading edge (Figure 3) to enable larger regions of laminar flow, and less skin friction drag. Both flow control concepts (AFC and IAM) contribute to the ERA project's goal of drag reduction for airframe technology. ${ }^{11}$

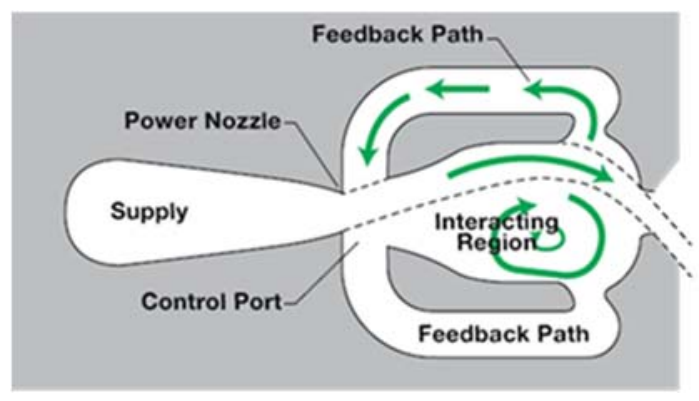

Figure 1 - Drawing of the components of a sweeping jet actuator

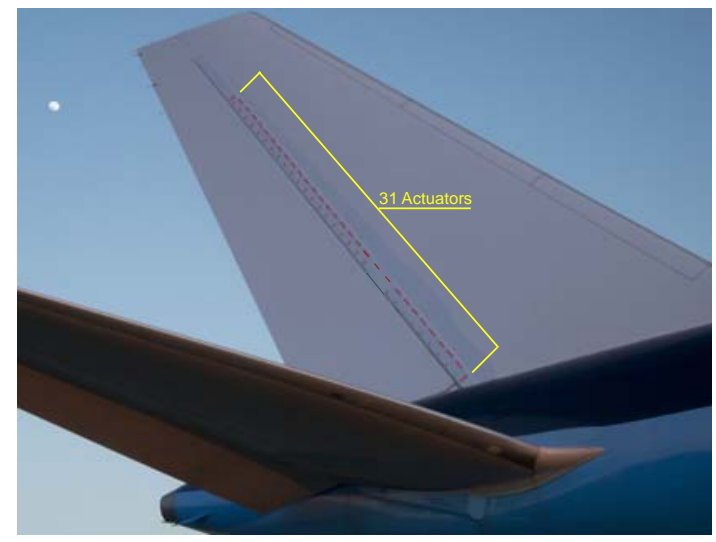

Figure 2 - Actuator arrangement on vertical tail

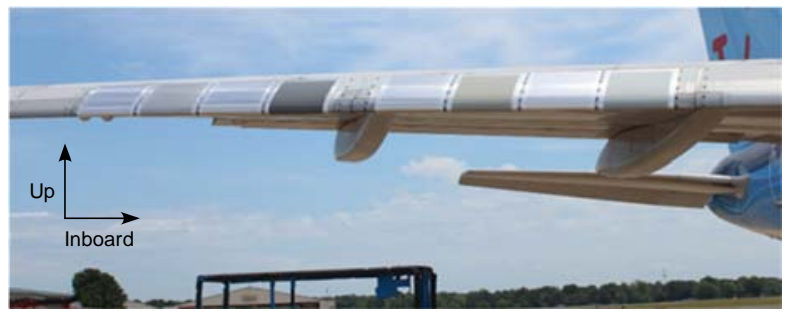

Figure 3 - Engineered Surface Panel layout

\section{Boeing 757 ecoDemonstrator Test Bed Aircraft}

The Boeing ecoDemonstrator Program is a multi-year effort to accelerate testing, refinement, and use of innovative technologies and methods that improve aviation's environmental performance. This program is focused on providing new, more environmentally efficient technologies and airplanes for Boeing's customers. The 757 was the latest in an ongoing series of ecoDemonstrator platforms.

The airplane, shown in Figure 4, was a Model 757-222 and was utilized after retirement from revenue service with United Airlines. The airplane was fitted with Pratt \& Whitney PW4037 engines leased from Delta Airlines. The port (left) engine was modified via Service Bulletin to increase the available thrust from 37,000 to 40,000 pounds during AFC testing for increased thrust asymmetry. The 757 was extensively modified for the duration of the test period. At the conclusion of the AFC and IAM flight demonstrations, Boeing delivered the aircraft to the Aircraft Fleet Recycling Association, which recycled the 757 using environmental best practices. 


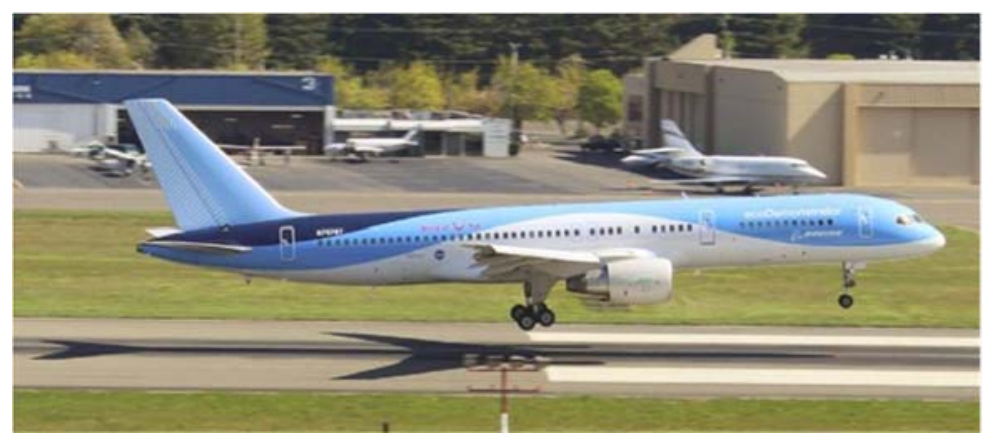

Figure 4 - The Boeing 757 ecoDemonstrator

\section{AFC System Design}

\section{System Architecture}

The AFC system consisted of ducting to obtain air from the APU, a control valve to modulate the air flow, a heat exchanger to lower the APU air temperature, and additional ducting to deliver the air to the AFC actuators located on the vertical tail. In addition, a duct in the system was calibrated to provide the primary means of calculating system mass flow. Pressure and temperature sensors were installed at key locations to monitor system performance and provide a means to detect a system leak or duct burst.

\section{AFC Objectives and Requirements}

A system design needs a clear set of verifiable requirements. A sample of AFC objectives and system requirements are listed below.

\section{Objectives}

- Demonstrate the ability to integrate a prototype AFC system into an airframe, and thereby highlight key integration challenges

- Demonstrate AFC impact on rudder effectiveness in flight using available APU flow rates

- Collect in-flight data for comparison to full-scale wind tunnel results and CFD predictions

\section{System Design Requirements}

- Minimal modifications to existing structures and systems

- Minimal relocation of existing flight-critical systems

- Accommodate installation and testing within the existing tail structure

- Decrease APU compressor air temperature below $130^{\circ} \mathrm{F}$ to protect structural integrity of rudder skin

- Accommodate thermal expansion in ducting components

- Maintain design standard clearances (static and dynamic sweep envelope requirements)

- Incorporate pressure and temperature sensors in major trunk lines

- Bond externally-mounted components to mitigate p-static and electromagnetic emissions risks

- Maintain fuselage skin temperature below $200^{\circ} \mathrm{F}$

\section{Auxiliary Power Unit (APU)}

The airplane's APU was selected as the air source for the AFC system after analysis of its pneumatic performance characteristics. NASA Ames wind tunnel testing concluded that the output range expected of the APU would be sufficient to provide the necessary system mass flow.

Use of the APU for AFC testing meant it had to be disconnected from the rest of the airplane's pneumatic bleed air system. This meant the APU compressor was not available for starting the engines, nor could it provide bleed air for the air conditioning packs. Once AFC testing was completed, the airplane's bleed air system was restored to its production configuration. 


\section{AFC Mass Flow Distribution System}

The mass flow distribution system, as shown in Figures 5 and 6, was designed to distribute the APU bleed air to the 31 actuators as consistently as possible along the span of the vertical fin and to incorporate sensors to measure pressure, temperature, and calculate mass flow of the system. The actuators were located a considerable distance from the APU, therefore, minimizing losses due to ducting bends and joints was an important requirement. This was accomplished to the greatest extent possible within the constraints of the existing aircraft structure.

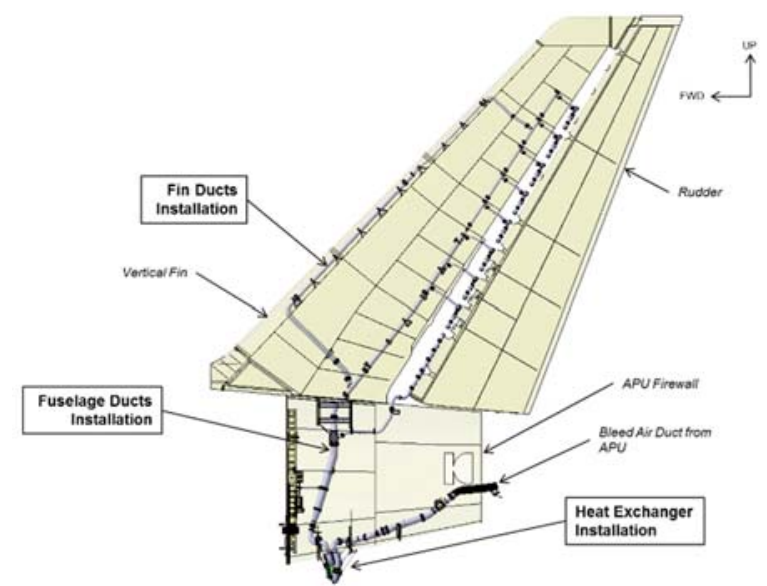

Figure 5 - Mass Flow Distribution System in Vertical Tail

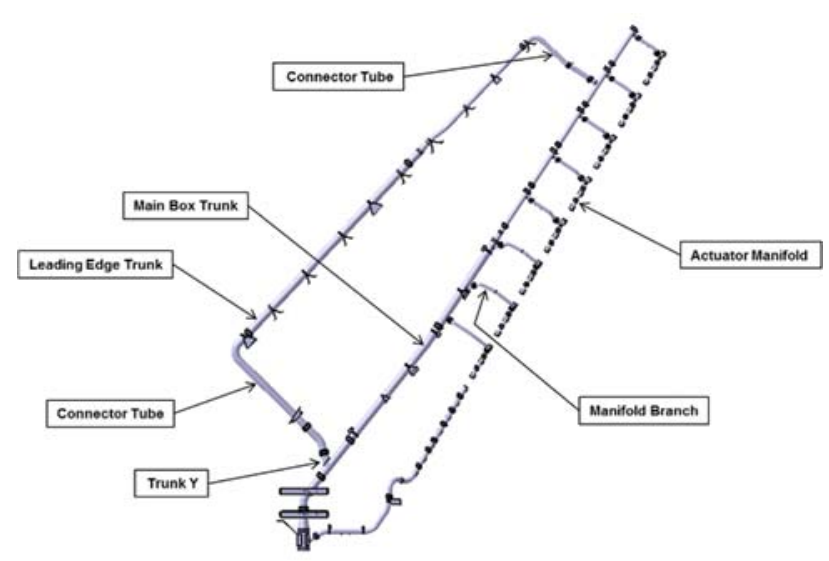

Figure 6 - Mass Flow Ducting Layout

The system mass flow was controlled by a valve located between the APU and the heat exchanger. It could be commanded to full-open, partially-open, and closed positions from a station in the airplane cabin, enabling collection of data at different mass flows.

To avoid exceeding structural temperature limits, an air-to-air heat exchanger (HX) was incorporated to reduce the APU bleed air temperature. The HX was previously qualified for use as part of the Environmental Control System (ECS) on the Boeing 757. As shown in Figure 7, the heat exchanger was mounted beneath the aft fuselage of the 757 ecoDemonstrator.

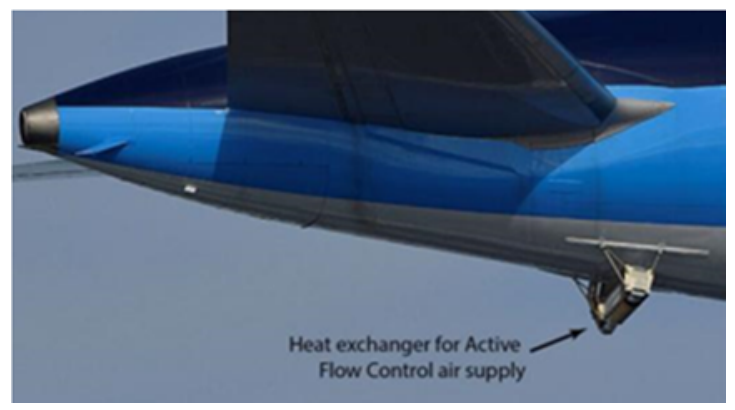

Figure 7 - Heat Exchanger Location

The majority of mass flow ducting was manufactured from 0.35” 321 CRES in diameters ranging from 1.0 to 6.0 inches. 321 CRES is the standard material used for tubing/ducting due to its strength, thermal properties, and cost. It was routed internally through the vertical tail structure (Figure 8) up to the NASA-provided sweeping jet actuators ${ }^{5}$. 

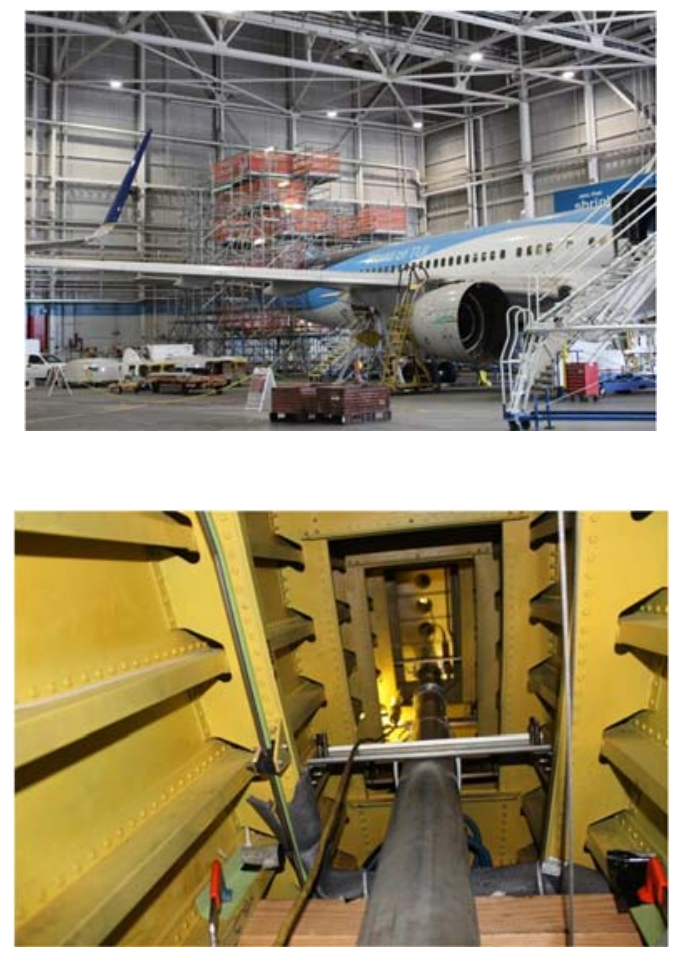
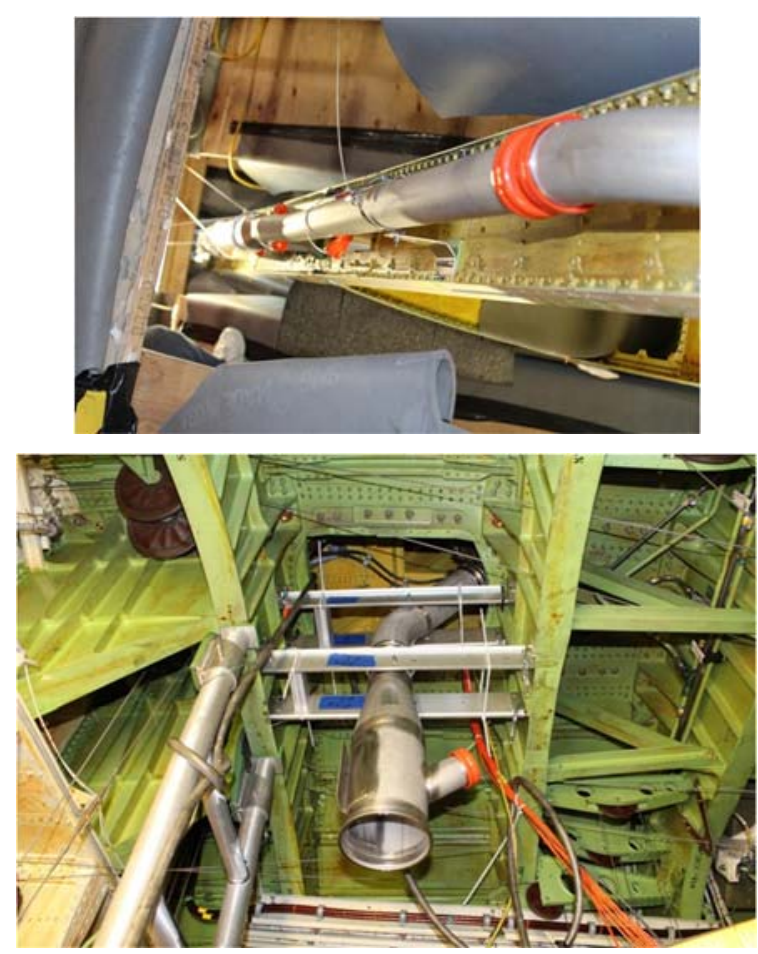

Figure 8 - AFC Ducting into the Vertical Tail

\section{AFC System Instrumentation}

The AFC system was fitted with pressure and temperature sensors to monitor and record mass flow and system performance. Figure 9 illustrates details of the AFC system instrumentation in the aft fuselage. The cold duct section was calibrated and used as the primary method of determining the system mass flow. The vertical stabilizer instrumentation details can be observed in Figure 10.

AFC flight test and aircraft state data were acquired using ADAMS (Airborne Data Analysis/Monitoring System) located within the 757 test aircraft. ADAMS is a Boeing proprietary rack-mounted system used to collect, record, and display data of interest during a flight test. The data can be analyzed in-flight and are easily downloaded for later review.

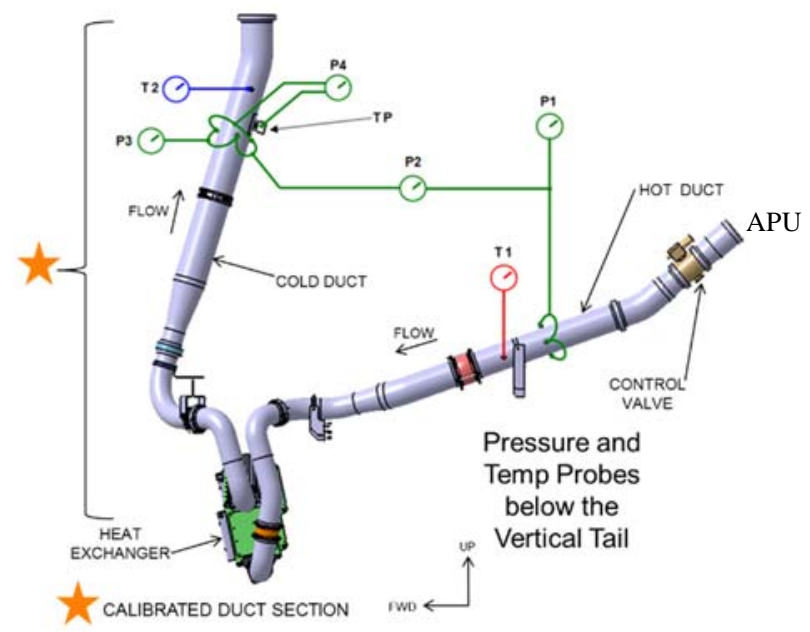

Figure 9 - Instrumentation in the Aft Fuselage

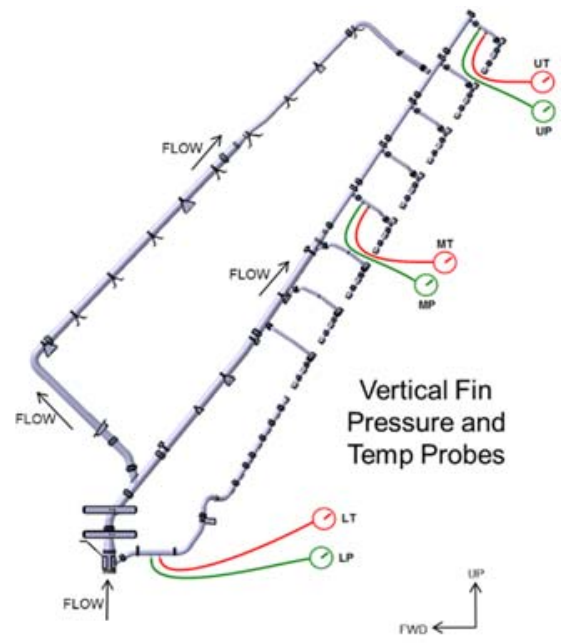

Figure 10 - Instrumentation in the Vertical Tail 


\section{AFC System Integration}

\section{Sweeping Jet Actuators}

The vertical tail actuators were split into 4 panels (Figure 11) to stay within machining table size limitations. Section 1 incorporated 7 actuators. Section 2 had one 7 actuator panel and one 2 actuator panel for a total of 9 actuators. Section 3 had one 7 actuator panel and one 5 actuator panel (Figure 12) for 12 total actuators. Section 4 contained one panel with 3 actuators and one blank section designed to maintain the same external geometry. The overall arrangement essentially duplicated the 37-actuator configuration tested in the NFAC wind tunnel. Tunnel testing revealed the 6 tip-most actuators had little effect. A blank panel was used in place of those actuators for flight testing and resulted in a total of 31 actuators

The thirty-one sweeping jet actuators were designed and fabricated at NASA Langley Research Center. The actuators were machined from 3/8-in. thick 6061-T651 aluminum (Figure 13) having a final chord-wise length of 7.5in. and a depth $1 / 4$-in. NASA chemically etched (Iridite finish per MIL-DTL-5541F, Class 1A) the actuators for painting prior to shipping to Boeing. To ensure that the NASA-built actuators interfaced correctly with the vertical tail, Boeing specified that each actuator plate incorporate 2 pilot holes for locating purposes, so that Boeing could match drill the actuator plates to fasten them to aluminum base plates. These panel assemblies were then mounted to the vertical fin of the airplane.

Manifolds as seen in Figure 14 were used to deliver mass flow (air) to the actuators.

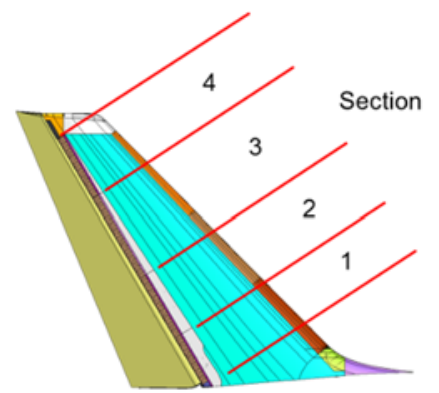

Figure 11 - Vertical Tail Actuator Panel Section

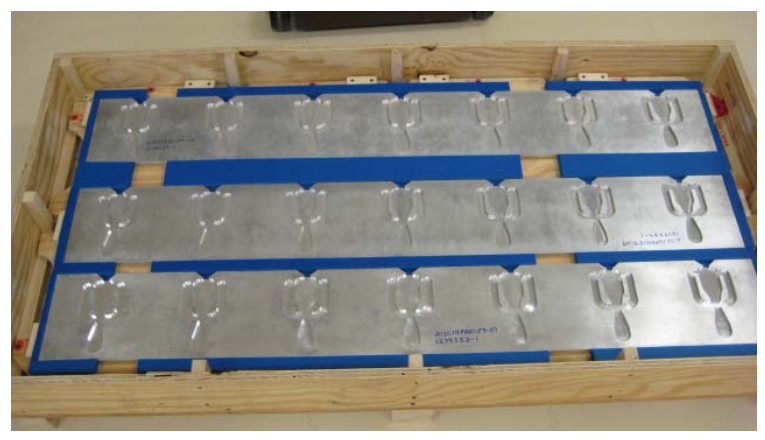

Figure 13 - Sweeping Jet Actuators in Shipping Crate

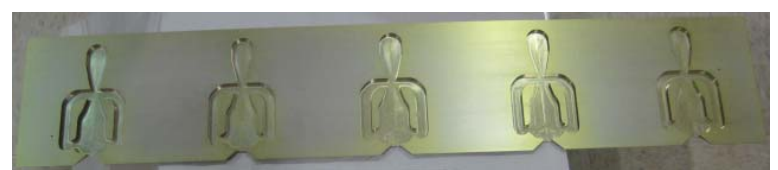

Figure 12 - Five Panel Iridite finish Actuator

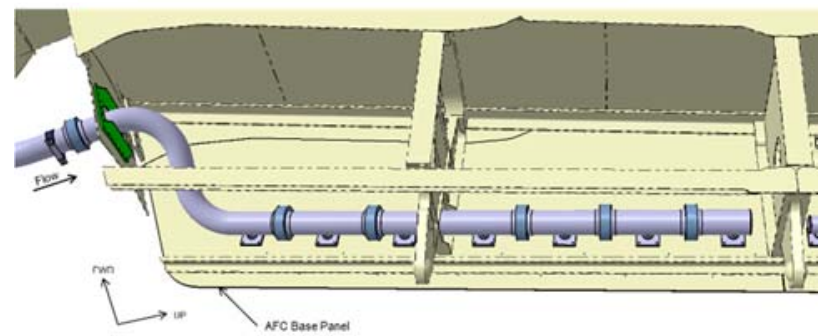

Figure 14 - Actuator Mass Flow Manifold 


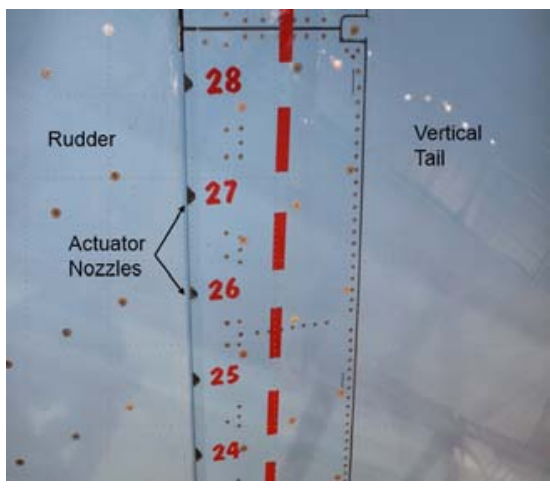

Figure 15 - Sweeping Jet Actuators installed

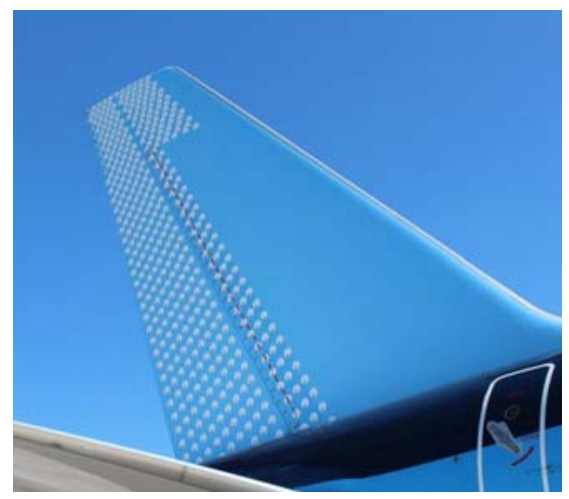

Figure 16 - Location of all 31 Actuators

Figure 15 shows the installed sweeping jet actuators. The 31 sweeping jet nozzles were located along the hinge line on the starboard (right) side of the trailing edge of the stabilizer, where the nozzles were aligned normal to the trailing edge and pointed downstream ${ }^{7}$ (Figure 16). The red dashed line shows the upstream end of the AFC actuator. The actuator numbers are placed just upstream of the actuator nozzles, and the dots located primarily on the rudder indicate where flow cones were later installed.

\section{System Integration}

AFC system hardware integration was difficult since the airplane had already been built. For example, ducting in the vertical fin was installed in multiple pieces due to limited access. Bends and branches had to be designed to fit within the existing geometry to minimize cutting structure. In a new airplane design, longer tubes and more optimized flow paths could be incorporated reducing both installation time and the number of couplers, saving weight. In addition to routing around structure, it was also necessary to mitigate interference with existing systems.

Careful design and stress analysis ensured the ducting would be able to withstand maximum loading during flight without leakage, and be able to accommodate thermal expansion due to the heated APU air. Similar analysis ensured the vertical tail would be able to withstand the additional weight of the ducting and side forces generated during test.

Since many ducting joints were required, periodic leak checks were performed during installation to ensure proper sealing. This disciplined approach saved time overall by eliminating the need to "chase leaks" at the end when access to repairs would have been much more difficult.

\section{AFC Ground Testing}

Prior to flight, Boeing conducted a series of laboratory and ground tests to verify that the heat exchanger, system controller, and overall AFC system worked as planned before it was flown.

\section{Heat Exchanger (HX)}

A ground vibration test was conducted by Boeing to establish the frequency response and vibration level limitations of the heat exchanger.

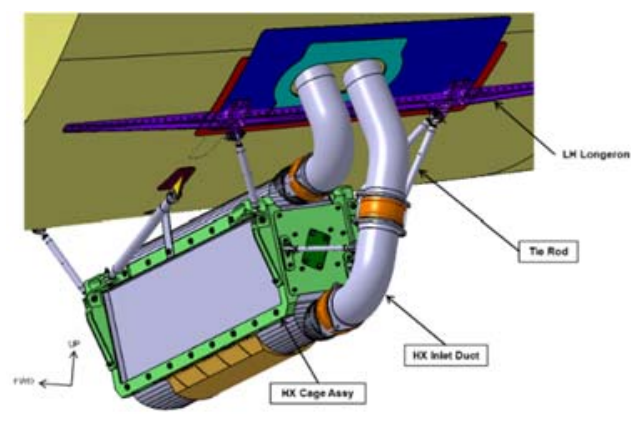

Figure 17 - Heat Exchanger Illustration

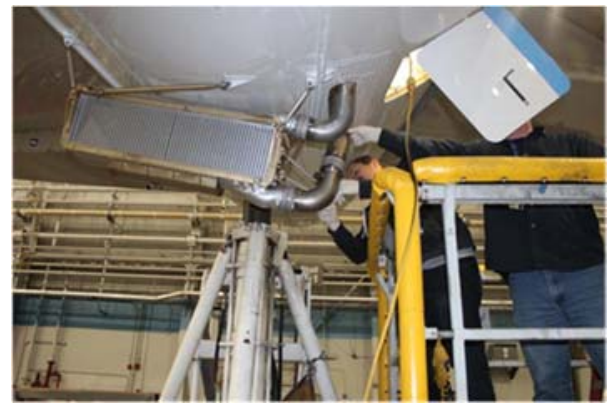

Figure 18 - Heat Exchanger Location on 757 (looking aft) 


\section{AFC Flow Valve and Valve Controller Integration}

Testing was conducted to verify the operation of the system controller and control valve using the in-cabin software graphical user interface (GUI) (Figure 19) used to control the AFC control valve (Figure 20) in flight. The GUI controller and the valve operated without incident. Electromagnetic Interference (EMI) testing was also conducted on the valve controller to ensure the controller would not interfere with any of the aircraft's systems.

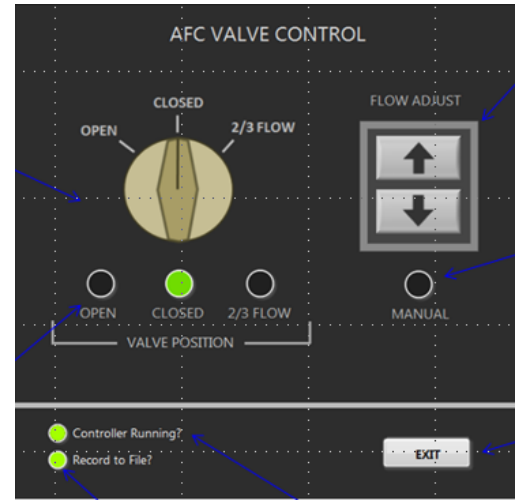

Figure 19 - Control Valve Crew Interface Panel

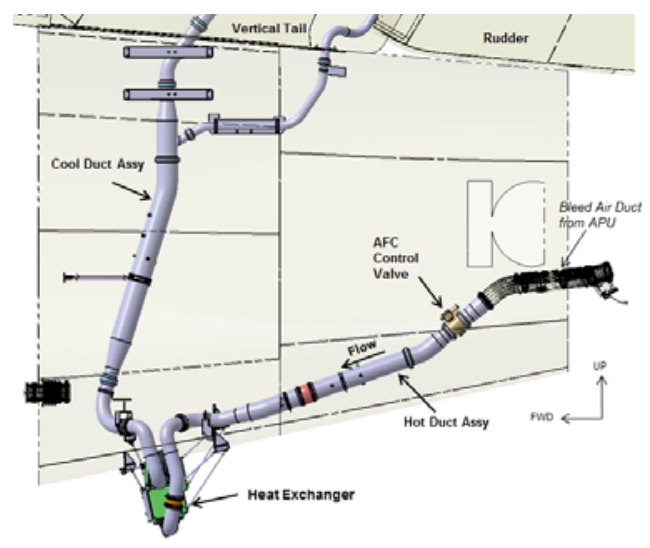

Figure 20 - Control Valve Location

\section{Duct Calibration}

It was necessary to calibrate the "cold duct" assembly to determine mass flow and other AFC system performance parameters from the pressure and temperature as seen in Figure 21. The cold duct assembly calibration occurred in a Boeing pneumatic laboratory (Figure 22). Calibration curves were created and used to determine mass flow.

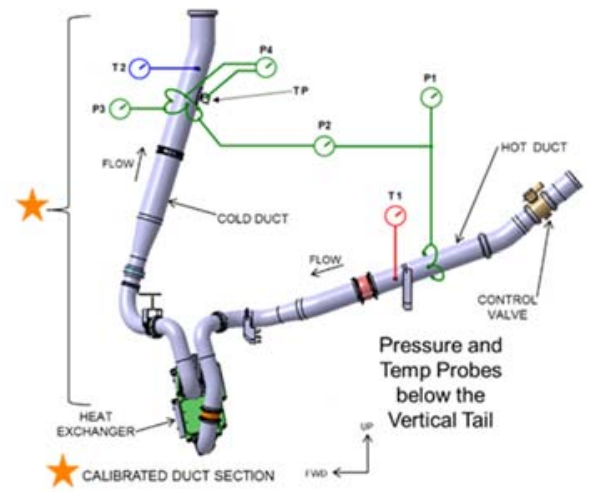

Figure 21 - Location of Calibrated Duct Section

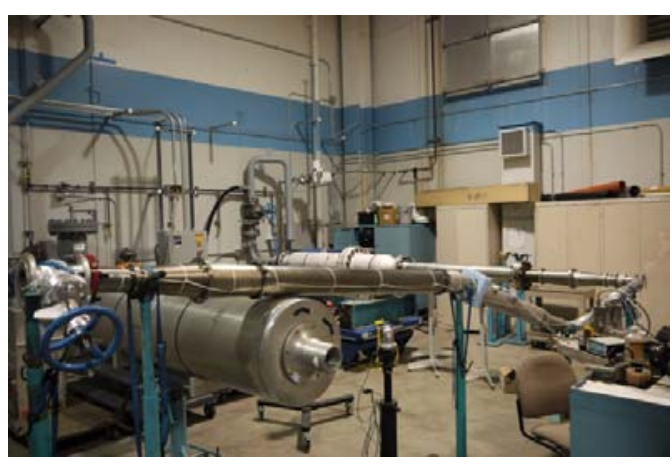

Figure 22 - Cold Duct Calibration Set up

\section{System Leak Tests}

As previously mentioned, Boeing performed leak checks at key points in the assembly. As leaks were discovered, appropriate correction processes were conducted until the leaks stopped. After the AFC system assembly was installed in the aircraft, a system leak check was completed and leaks were corrected with no further concerns.

\section{AFC Ground Test and System Functionality Check}

A system functionality check was conducted prior to flight. This system check included measuring AFC actuator output (Figure 23) and span-wise homogeneity of the flow output from the 31 AFC sweeping jets actuators located on the tail. It also ensured the system was controllable, instrumentation operated nominally, and established the system operation process. 


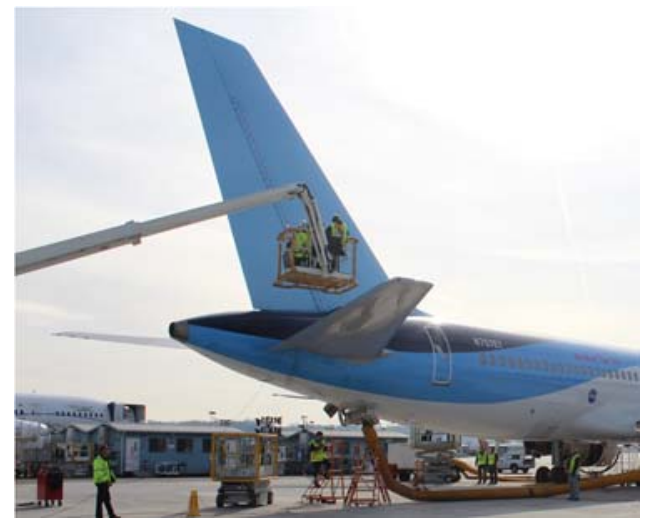

Figure 23 - Measuring Flow Output from the Sweeping Jet Actuators

\section{AFC Flight Demonstration}

\section{Site Location}

Flight conditions necessary to demonstrate AFC effectiveness required that testing be performed over water with visual flight rules. The Strait of Juan de Fuca was chosen based on the following criteria: a) anticipated lost days using meteorological analysis of historical weather patterns, b) cost effectiveness for flight crew and test crew, and c) compatibility and availability of chase plane for flow visualization photography. The Strait is the body of water separating Washington State from Vancouver Island, British Columbia, Canada (Figure 24).

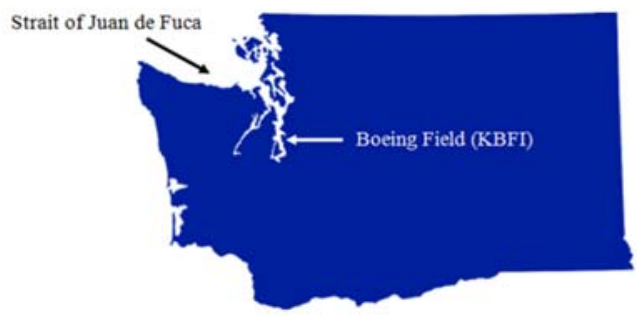

Figure 24 - Map of Washington State depicting Boeing Field and the Strait of Juan de Fuca

\section{AFC Flight Test Results}

Four days of AFC flight testing were completed, which composed of six flights in total. All flights originated from and returned to KBFI (Boeing Field - King County International). Photos of the flow cones were digitally overlaid to provide an enhanced composite snapshot of the air flow during a given test condition. Figure 25 illustrates the difference in flow field with AFC off and on $^{8}$. When AFC was on, the cones' orientations indicate that AFC is positively affecting the air flow over the rudder.

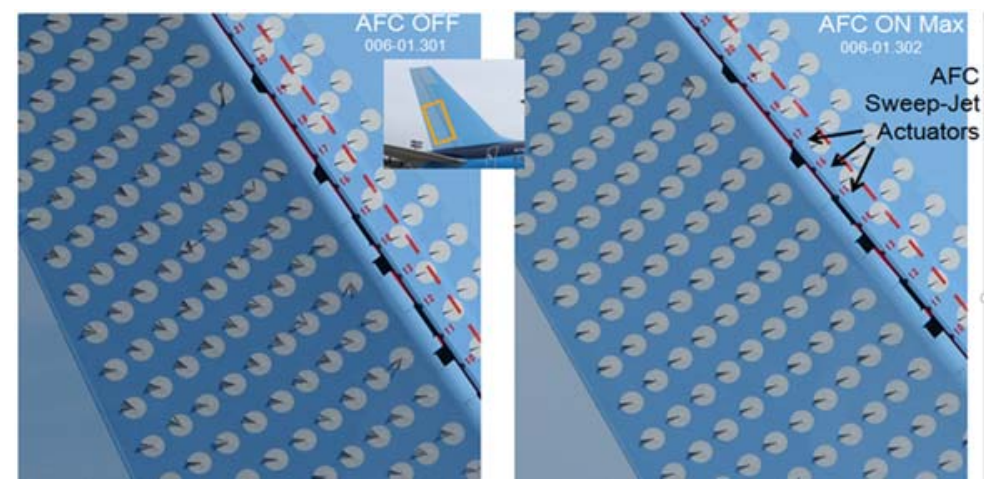

Figure 25 - Images of vertical fin flow cones with AFC off (left) and AFC on (right) 


\section{IAM System Design}

\section{IAM Objectives and Requirements}

A clear set of verifiable requirements is necessary for a system design. A sample of the IAM measurement objectives and system requirements is listed below.

\section{IAM System Objectives}

- Demonstrate Insect Accretion Mitigation (IAM) techniques that enable practical application of natural laminar flow through reduced insect residue accretion

- Monitor in-flight insect accretion buildup to determine when insect encounters are most likely to occur during the flight profile

\section{IAM System Requirements}

- Obtain flight test data at relevant flow (flight) conditions for flights on which selected insect impact protection materials are flown

- Assess the IAM effectiveness using flight test and ground inspection data

- Define a site selection criteria and recommend a flight testing site

- $\quad$ Flight test the Engineered Surfaces and control panels on slats 8 and 9 on the right wing of 757 ecoDemonstrator

- Provide cameras with a resolution of 1-mm x 1-mm square on the 757 ecoDemonstrator slats 8 or 9 with a minimum of 9 pixels

- Provide cameras with a frame rate of 1 picture per second

- Limit the weight of each camera and its mount to not to exceed 15-lbs

- Recommend a substrate panel material, size, and shape

- Size substrate panels to allow installation at any position on slats 8 and 9

- Satisfy safety of flight and airworthiness requirements

- Apply IAM coatings to the substrate material using the application process

- Mark each Engineered Surface and control panel into sections of equivalent frontal area

- Remove and transport post flight the Engineered Surfaces and control panels to an inspection area without damaging the insect residue

\section{Camera System Development and Integration}

\section{Camera Mounting Location Determination}

Several camera internal mounting locations were discussed by the NASA and the Boeing IAM team to meet the camera requirements. It was agreed that mounting the cameras inside the fuselage would allow access to the cameras during the flight test to change the camera storage media or change camera settings as necessary. The camera locations chosen were windows 2 and 3 on the starboard side of the aircraft (Figure 26). This location allowed a camera to be dedicated to either slat 8 or slat 9 . The disadvantage to this location was the 70 -foot distance between the windows and the slats (Figure 27).
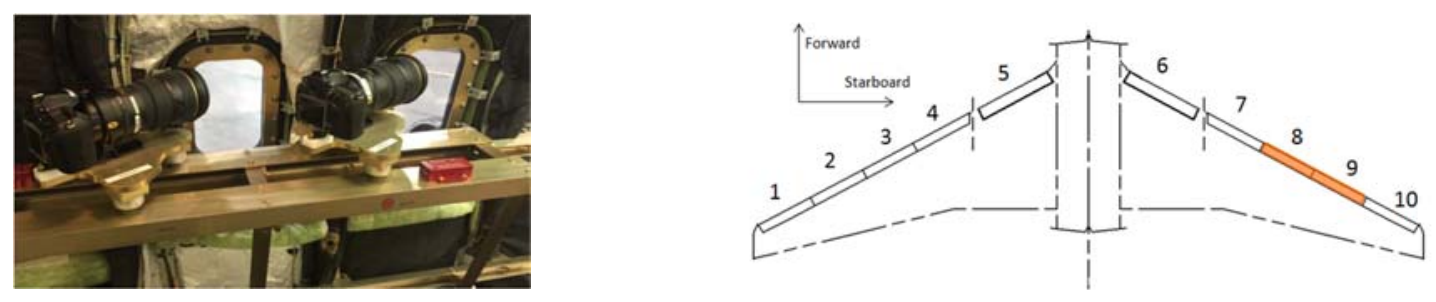

Figure 26 - Camera and Slat Location 


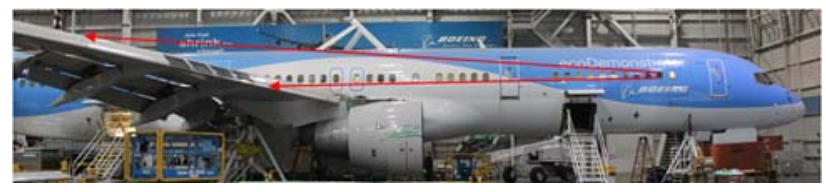

Figure 27 - 70-ft Slant Distance from the Cameras to Slats 8 and 9

\section{Camera System Trade Study}

NASA performed camera and lens trade studies using a slat mock-up (Figure 28) determine whether the camera and lens could meet a 1.0-mm x 1.0-mm camera resolution requirement (Figure 29). Boeing provided the slant distance (70-ft) and angle measurements between windows 2 and 3 and slats 8 and 9 which were used to locate the camera from the slat mock-up. The trade studies determined a Nikon D800E combined with the Nikon AFS-NIKKOR $300 \mathrm{~mm} \mathrm{f} / 2.8 \mathrm{G}$ ED VRII lens met the camera requirements.

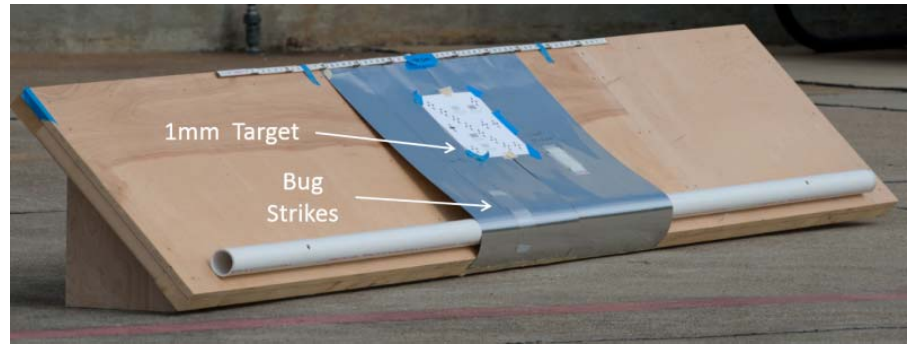

Figure 28 - Slat Mock-Up
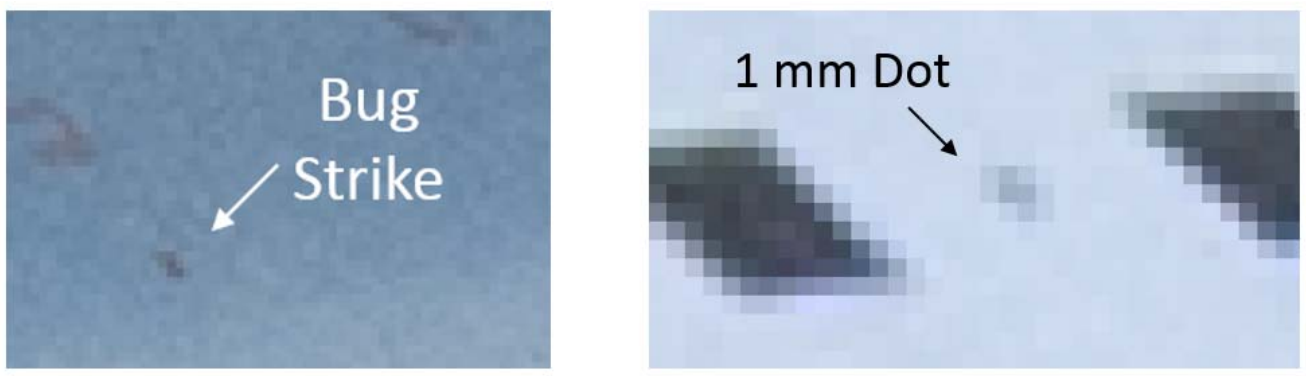

Figure 29 - Bug Strike and $1.0 \mathrm{~mm}$ dot at 70 feet

\section{Camera Mount Designs}

Reducing image blurring due to aircraft vibration presented a challenge for the IAM team. Boeing engineers provided preliminary vibration data that was critical at defining the anticipated vibration environment the camera may encounter during flight. To minimized aircraft induced vibrations, Boeing provided a modified camera table and NASA provided camera interface mounts with vibration isolators installed on its feet (Figure 30). In addition to vibrations reduction methods used above, the Nikon lens image stabilization mode would be utilized during flight. The vibration reduction strategies were verified during 757 check flights prior to IAM testing and no further modifications were required.

Tapered aluminum blocks were added between the vibration isolators and the camera mounting plate to adjust the camera pitch angle after installation. To enhance the picture quality, the Boeing standard window was replaced with an optically clear acrylic material. 

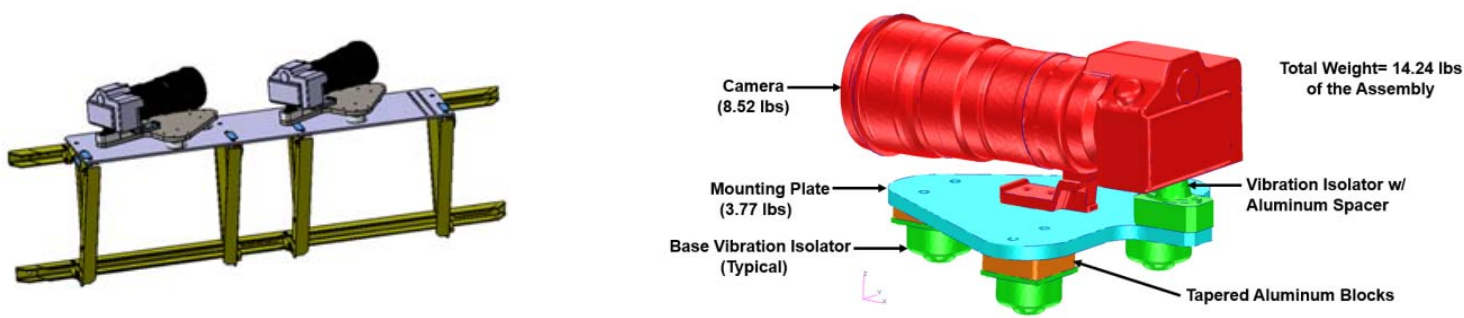

Figure 30 - Camera Table and Mount Design

\section{Engineered Surface Development and Integration}

\section{Engineered Surface Description}

Five NASA non-adhesion surface treatments (coatings) were chosen to evaluate their effectiveness at reducing insect accretions on the Boeing 757 ecoDemonstrator. The coatings were sprayed on substrate panels made from 7075-T6 clad aluminum panels (27-in x 30-in x 0.012-in) as illustrated in Figure 31. Once the coatings were sprayed on the substrate panels, the combination became an ES. Accompanying the ES were control panels which are substrate panels without coatings. The ES and control panels were arranged in an alternating pattern as seen in Figure 32 and attached to slats 8 and 9 on the right wing of the Boeing 757 ecoDemonstrator as shown in Figure 32.

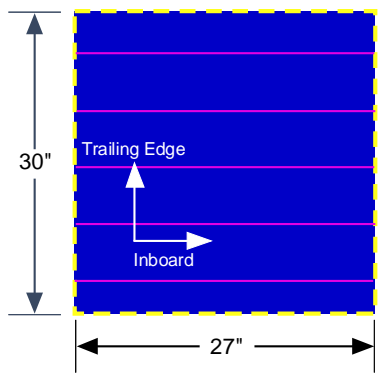

Figure 31 - Aluminum Substrate Panel Size

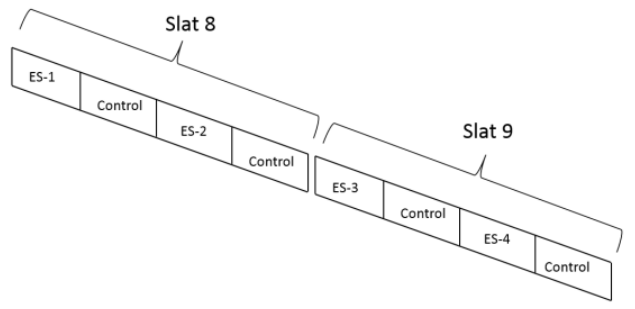

Figure 32 - - IAM Engineering Surface Layout

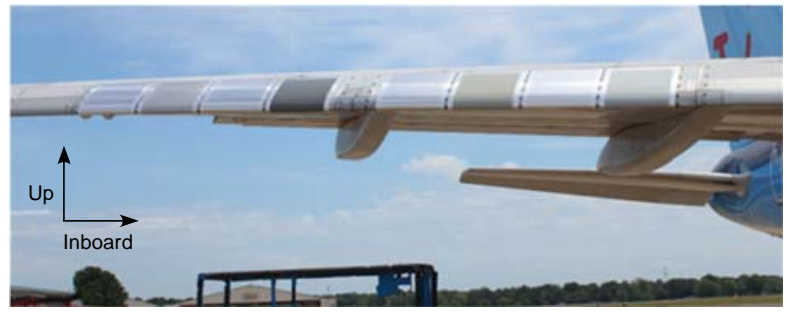

Figure 33 - Installed ES and Control Panels

\section{IAM Coating Downselection Process}

Over 200 surface coatings were evaluated at NASA Langley Research Center (LaRC) using a small scale wind tunnel $^{10}$ which allowed insects to be delivered at $\sim 150 \mathrm{MPH}$ onto a simulated wing leading edge. The coating performance success criteria were based on the insect residue areal coverage as measured by profilometry. Ultraviolet (UV) and durability tests were performed on the coatings to further downselect the potential IAM coatings. Following the UV and durability testing, NASA LaRC conducted another low speed wind tunnel test in the NASA LaRC Basic Aerodynamic Research Tunnel (BART) to further downselect the coatings. Following the BART test, low altitude flight tests was conducted using the NASA LaRC Hu-25 Falcon aircraft. Based upon the Falcon flight test results, five coatings were downselected for the IAM 757 ecoDemonstrator flight demonstration. 


\section{Coating Application Procedure Development (Sprayouts)}

Boeing conducted a series of sprayouts to develop and verify the application procedures (Figure 34) for the NASA coatings on the aluminum substrate panel that were flight tested on the 757 ecoDemonstrator flight.
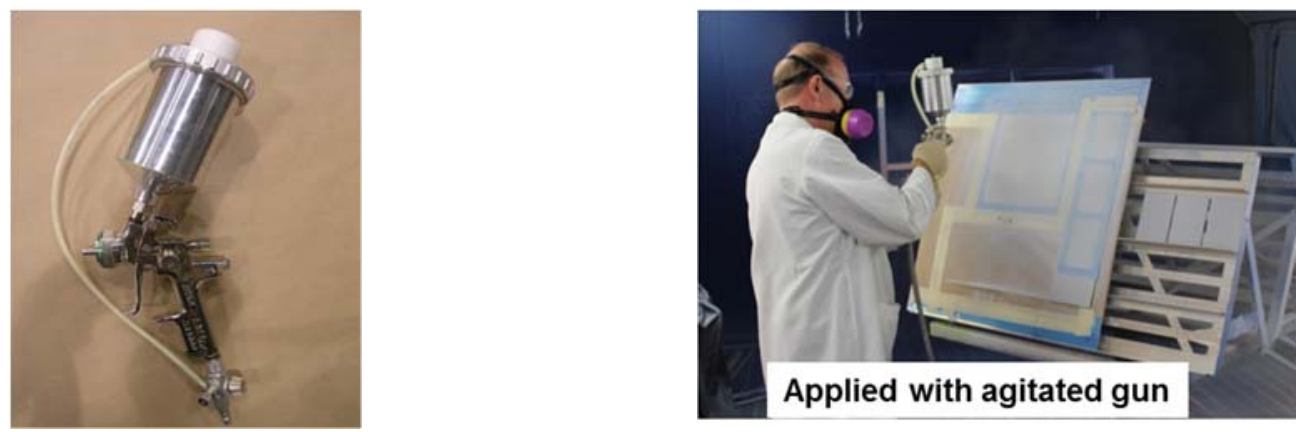

Figure 34 - Developing Sprayout Procedure

Some specific concerns and questions addressed by the preliminary sprayouts were:

1) What formulation (coating) quantities are needed for producing the coated panels for the flight test?

2) What mixing protocol is needed to produce the liter-size quantities that would provide consistent and uniform mixes?

3) How to mount and orient substrate panels for formulation application?

4) What paint gun setting or modifications are needed to apply a uniform film build during each coating pass?

5) How many application passes are needed to produce the desired cured coating properties?

6) What changes in solvent amount or solvent system are needed to establish a formulation that could be applied with ten to 20 minutes between passes?

7) How much time to allot for flash off the coated panels prior to cure?

8) How to orient the coated panels in the cure oven?

9) What is the correct cure protocol for each formulation?

Lessons learned from the series of sprayouts led to a successful application procedure. A total of 37 ES were sprayed for the flight demonstration.

\section{Engineered Surface Panel Installation}

Boeing conducted a trade study to determine the optimum ES and control panel attachment/installation method to the slat's outer surface. Boeing determined by applying double-sided adhesive tape to the back side of the substrate panel was the best solution. The adhesive tapes chosen required low enough adhesion strength to allow removal of the substrate without plastic deformation, yet strong enough to withstand the aerodynamic loading. This allowed the panels to be removed without damaging the insect residue data. Testing determined $3 \mathrm{M}^{\circledR}$ repositionable tape $9425 \mathrm{HT}$ as the best practical solution. One side of the tape had a high strength adhesive (45oz/in. peel strength) and the other side had a low strength adhesive (12 oz/in. peel strength). The high temp (HT) tape was chosen due to panel exposure to solar radiation and temperatures. The HT material is rated for $250^{\circ} \mathrm{F}$ versus $125^{\circ} \mathrm{F}$ for standard 9425HT tape.

Grounding requirements for p-static were met by including a small piece of copper tape on each panel. The edges of the ES were sealed with tape to prevent edge peeling from aerodynamic forces.

The lower surface crept and disbonded from the slat due to the stiffness of the substrate panel during ES installation procedural development. To alleviate creep concerns on the lower surface, a 2-in strip of high strength (96 oz/inch) double-sided, pressure-sensitive adhesive tape was added. This portion of the panel was not be subjected to insect accretion so plastic deformation during removal was acceptable.

The ES and control panels were vacuum bagged during their installation to ensure full bonding adhesion to the slats and to reduce voids. The ES and control panels were vacuum bagged for a minimum 1 hour at a minimum of 22-inches Hg to ensure full adhesion strength (Figure 35). 


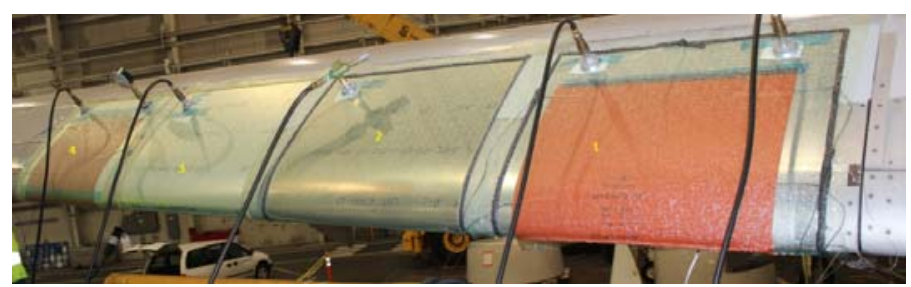

Figure 35 - Vacuum Bagging of Substrate on Slats

\section{Engineered Surface and Control Panel Removal}

The tape around the panel periphery and copper grounding tape were removed as illustrated in Figure 36. The removal of the ES and control panel began at the lower trailing edge and was peeled away from the slat surface using a plastic or phenolic wedge or scraper to separate the tape from the slat surface.

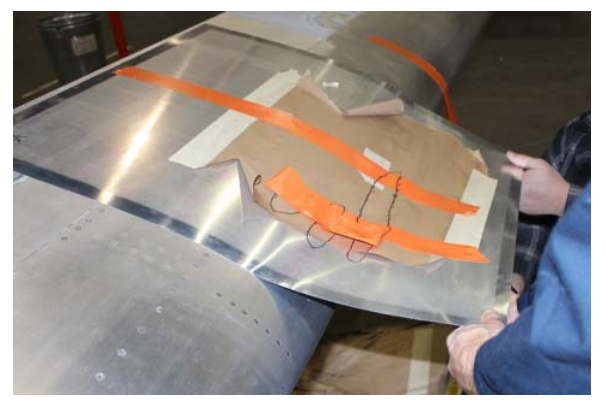

Figure 36 - ES Panel Removal from Slat (Upper Surface View)

\section{IAM Flight Demonstration}

\section{IAM Flight Test Site Selection}

A risk of encountering minimal insects that would meet the NASA-defined insect density criterion of 25 strikes per square foot was identified. The ability to collect a statistically significant dataset to assess the performance of the different IAM coatings could be compromised without adequate insect activity. A search for an optimum testing site was conducted to mitigate the risk and increase the probability of success. A site selection team composed of members from NASA, Boeing, Volpe, and The University of California, Davis, identified criteria to make an assessment of the viability of different sites and to downselect airports. Those criteria included physical attributes, meteorological attributes, and insect population and density to make quantitative site assessments. Detailed site selection criteria are summarized below.

\section{1). Physical Attributes}

- $\quad$ Airport within the continental U.S.

- $\quad$ Runway length to support the B757 (>8,000ft)

- Low, day time air traffic operations $<500$ aircraft per day

- $\quad$ ATC control tower

- $\quad$ Airspace availability

- Wetlands or agricultural areas nearby

2) Meteorological Attributes - (monthly)

- $\quad$ Number of non-flying days (e.g., amount of rainy days)

- Daily temperature range between 65 and 90 degrees Fahrenheit during daylight hours for a minimum 4 hour window

- $\quad$ Humidity $>30 \%$ during daylight hours

- $\quad$ Little or no wind over $10 \mathrm{kts}$ for a minimum 4 hour window

- $\quad$ March - May 2015 target months 


\section{3) Insect Population Likelihood}

- $\quad$ Recommendation by month as to the likelihood of highest insect strikes based on physical and weather attributes

Based on the historical data, the initial airport list was reduced from 86 airports in 15 states to 6 airports in 3 states. The team conducted site visits of each airport on the dates shown in Table 1.

\section{Table 1 - Site Visits}

\begin{tabular}{lc}
\multicolumn{1}{c}{ Airport } & Date of Visit \\
\hline Tallahassee, FL (KTLH) & $4 / 14 / 2014$ \\
Fort Myers, FL (KRSW) & $4 / 16 / 2014$ \\
Stockton, CA (KSCK) & $4 / 22 / 2014$ \\
Fresno, CA (KFAT) & $4 / 23 / 2014$ \\
Shreveport, LA (KSHV) & $4 / 29 / 2014$ \\
Alexandria, LA (KAEX) & $4 / 30 / 2014$
\end{tabular}

The site selection team independently ranked the sites at the conclusion of the site visits. The site selection team recommended Shreveport, LA, with Alexandria, LA, as the secondary location. The recommendation was submitted to and accepted by Boeing.

\section{IAM Flight Profiles}

The flight profiles were selected to maximize insect accretion while flying a variety of takeoff conditions to simulate actual airline operations. The leading edge flaps of both wings were fully deployed and were not retracted during the test. To achieve a range of climb rates and speeds, takeoffs were performed at a range of trailing edge flaps angles. Final climb altitudes varied between 1,500 and 10,000 feet. Fifteen IAM test flights were conducted.

\section{Engineering Surface Inspection Post Flight}

Selected crew members aboard the 757 ecoDemonstrator monitored the on-board camera data during the flight. Once it was ascertained the control panels met the insect density criterion of 25 strikes per square foot, the 757 returned to Shreveport and landed. With the flight crew still on-board, NASA and Boeing researchers on the ground verified the insect density criterion on the IAM control panels had been met.

To ensure an insect density criterion of 25 strikes per square foot was met, a square foot template was used to aid in the counting, however, it proved to be difficult to use. Markings on the control panels split each panel into equivalent frontal area zones to assist onboard accumulation monitoring. NASA and Boeing created a new process to confirm whether the insect density criterion were met by counting the number of insect hits in zones 2 and 3 . The process also changed the insect density criterion from 25 strikes per square foot to a total count between 53 to 62 hits in both zones per panel. This process reduced the time to confirm the density count.

If the insect density criterion were not met, the flight crew would takeoff and conduct additional sorties until the onboard data indicated the density criterion was met. The flight was completed if the ground count verified the criterion were met. All the ES and control panels were photographed, had an in situ accretion count, were removed from the slats, and were delivered to NASA for a detailed insect count. In addition, an entomologist identified the various insects that had impacted the panels. Figure 37 outlines the zone numbering used; note Zone 0 is the underside of slat below the first white line. Figure 38 is an example of an in-flight photograph showing insect hits. Figure 39 is a sample of laboratory inspection photographs of an ES after aircraft removal. 


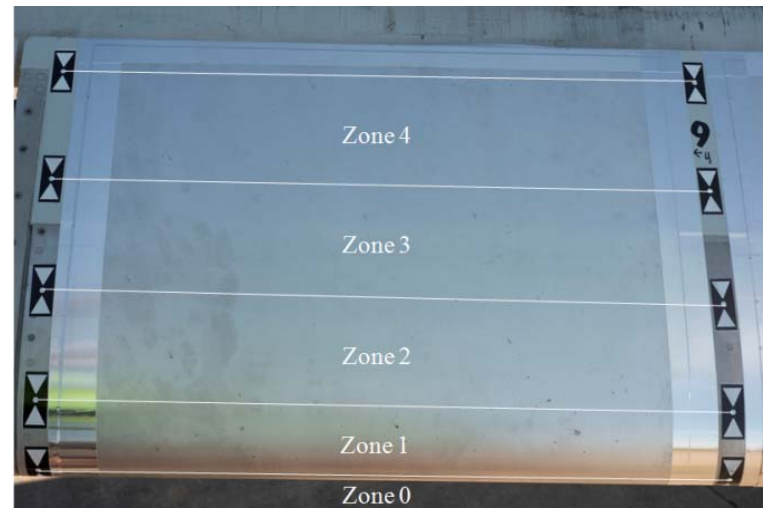

Figure 37 - Panel Zone Numbering (View from Above)

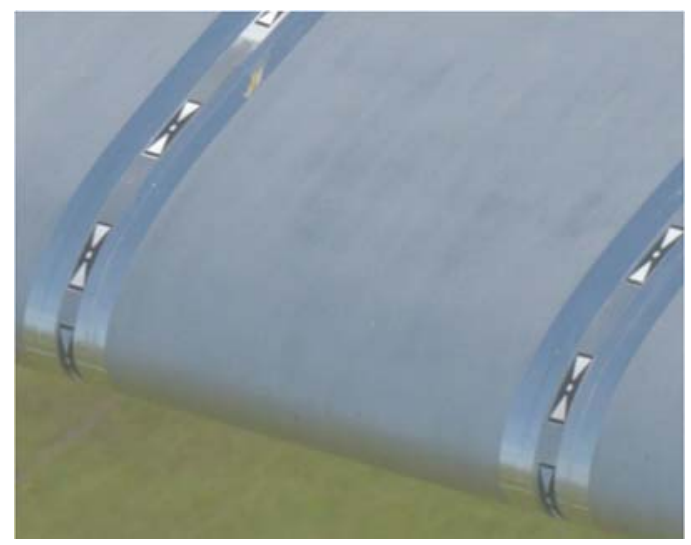

Figure 38 - Example of in-flight Photo

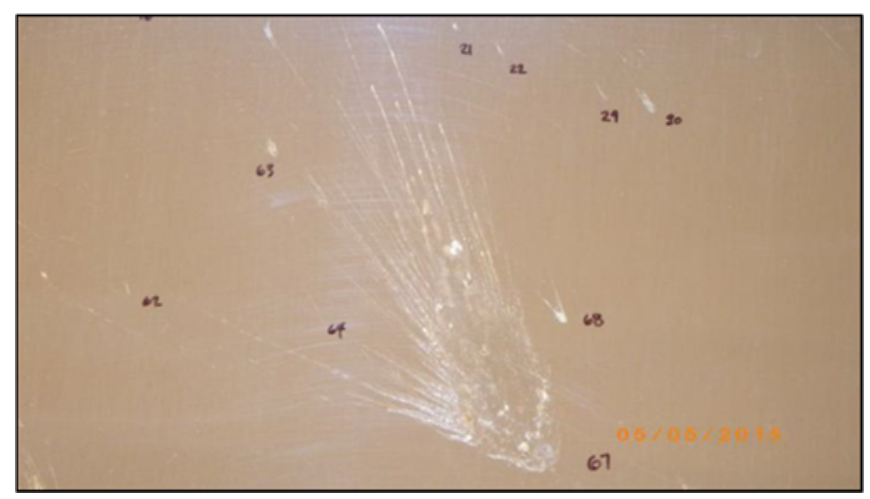

Figure 39 - Post-flight ES Insect Residue Inspection Photo

\section{IAM Flight Tests Results}

Fifteen IAM 757 ecoDemonstrator flight tests were conducted testing five different surface treatments (coatings). Insect accretion counts were recorded by panel and slat zone. An example inspection count from a single flight is shown in Table 2.

Table 2 - Flight 7 Insect Count ${ }^{12}$

\begin{tabular}{|c|c|c|c|c|c|c|c|c|}
\hline \multirow{2}{*}{ ZONE } & \multicolumn{4}{|c|}{ Slat 9} & \multicolumn{4}{c|}{ Slat 8} \\
\cline { 2 - 9 } & CONTROL & TEST & CONTROL & TEST & CONTROL & TEST & CONTROL & TEST \\
\hline $\mathbf{4}$ & 38 & 18 & 56 & 23 & 35 & 18 & 37 & 26 \\
\hline $\mathbf{3}$ & 56 & 23 & 52 & 47 & 46 & 35 & 42 & 31 \\
\hline $\mathbf{2}$ & 65 & 27 & 65 & 48 & 54 & 35 & 60 & 65 \\
\hline $\mathbf{1}$ & 54 & 43 & 57 & 57 & 54 & 38 & 67 & 56 \\
\hline $\mathbf{0}$ & 9 & 12 & 18 & 11 & 15 & 10 & 12 & 5 \\
\hline \hline TOTAL & 222 & 123 & 248 & 186 & 204 & 136 & 218 & 183 \\
\hline
\end{tabular}

When the accretion totals are normalized by the frontal area of each zone, as shown in Figure 40, typical counts showed a higher accretion rate in the zones near the leading edge highlight. The spanwise variation in accretion rate did trend lower moving from outboard to inboard, towards the engine. However, this variation was not significant using the method of comparing the coated ES panels with the neighboring uncoated control panels. Figure 41 summarizes the coatings' results. The best IAM coating (IAMC-5B) demonstrated up to a $37 \%$ average reduction in insect accretion over the control panels. 


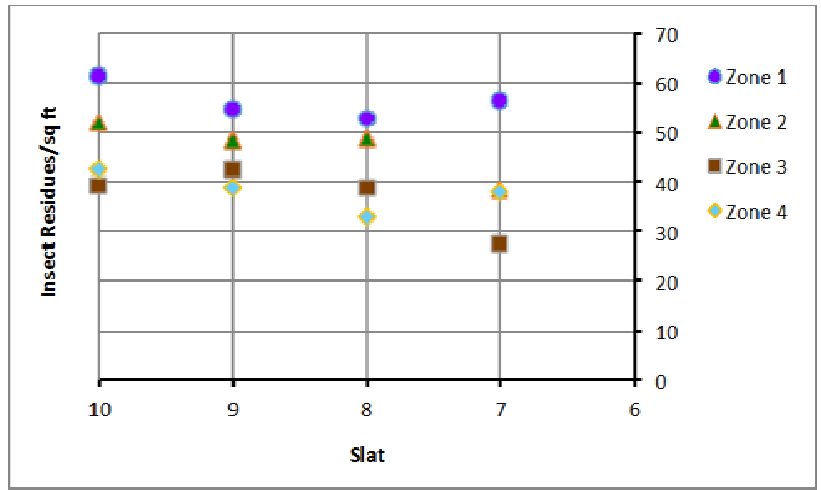

Figure 40 - Average Residue Accretion of Uncoated Surfaces Normalized by Frontal Area

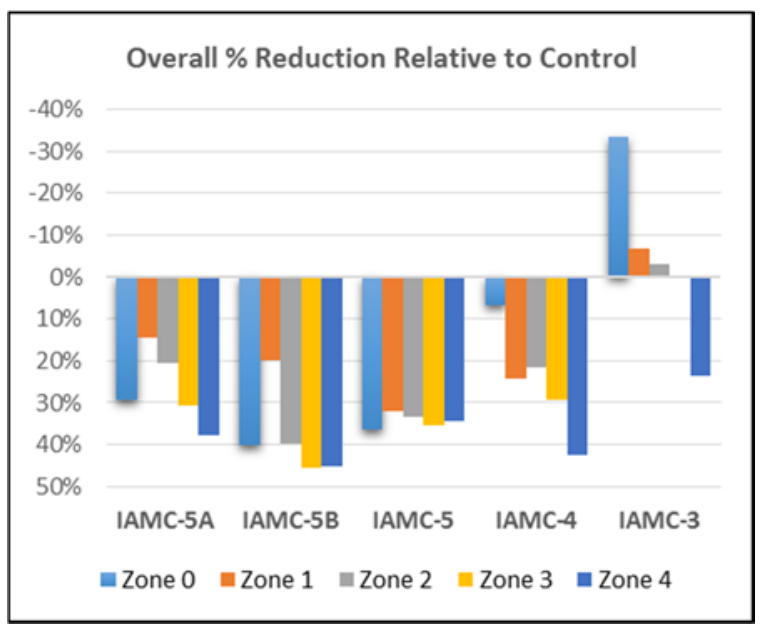

Figure 41 - Percent Reduction Relative to Control

\section{Conclusion and Recommendations}

The AFC system was designed, fabricated, and integrated on the 757 ecoDemonstrator aircraft, and flight demonstrated the effectiveness of active flow control technology. All requirements were verified and met. Operation of the AFC system resulted in performance within predictions and capable of establishing reproducible conditions. It is recommended an AFC integration system study and further system development be accomplished to ensure a viable and manufacturable AFC system for future commercial operations. The stakeholders' expectations were met.

The IAM system was designed, fabricated, and integrated on the 757 ecoDemonstrator aircraft, and flight demonstrated the effectiveness of insect phobic coatings in flight. All requirements were verified and met. The IAM Engineering Surfaces (ES) method of coating attachment and installation on the 757 ecoDemonstrator aircraft was demonstrated. Insect accretion flight data demonstrated a significant insect accretion reduction when compared to the control. It is recommended further study be required to evaluate and optimize the coating's long term viability, reliability, durability, and repairability. The stakeholders' expectations were met.

\section{References}

${ }^{1}$ Collier, F. S., Thomas, R., Nickol, C. A., Lee, Chi-Ming, and Tong, M., "Environmentally Responsible Aviation - Real Solutions for Environmental Challenges Facing Aviation," 27th International Congress of the Aeronautical Sciences, Paper No. 802, Nice, France, September 19-24, 2010.

${ }^{2}$ Bezos-O’Conner, G. M., Mangelsdorf, M. F., Maliska, H. A., Washburn, A. E., and Wahls, R. A., "Fuel Efficiencies Through Airframe Improvements,” AIAA 2011-3530, 29th AIAA Applied Aerodynamics Conference, Honolulu, HI, June 27-30, 2011.

${ }^{3}$ Bushnell, D. M., "Overview of Aircraft Drag Reduction Technology," in Special course on skin friction drag reduction, AGARD Report 786, 1992.

${ }^{4}$ Bushnell, D. M., and Tuttle, M. H., "Survey and Bibliography on Attainment of Laminar Flow Control in Air using Pressure Gradient and Suction,” Vol. I, NASA RP-1035, 1979.

${ }^{5}$ Raman, G., and Raghu, S., “Cavity Resonance Suppression Using Miniature Fluidic Oscillators”, AIAA Journal, Vol. 42, No. 12, December 2004, pp. 2608-2611.

${ }^{6}$ Lin, J. C., Andino, M. Y., Alexander, M. G., Whalen, E. A., Spoor, M. A., Tran, J. T., and Wygananski, I. J., "An Overview of Active Flow Control Enhanced Vertical Tail Technology Development," AIAA Paper No. 20160056, 53 ${ }^{\text {th }}$ AIAA Aerospace Sciences Meeting (SciTech 2016), January 4-8, 2016.

${ }^{7}$ Whalen, E. A., Lacy, D., Lin, J. C., Andino, M. Y., Washburn, A. E., Graff, E. C., and Wygnanski, I., "Performance Enhancement of a Full-Scale Vertical Tail Model Equipped with Active Flow Control," AIAA Paper 
No. 2015-0784, 53 ${ }^{\text {rd }}$ AIAA Aerospace Sciences Meeting (SciTech 2015), January 5-9, 2015.

${ }^{8}$ Andino, M. Y., Lin, J. C., Washburn, A. E., Whalen, E. A., Graff, E. C., and Wygnanski, I., "Flow Separation Control on a Full-Scale Vertical Tail Model using Sweeping jet Actuators," AIAA Paper No. 2015-0785, 53 ${ }^{\text {rd }}$ AIAA Aerospace Sciences Meeting (SciTech 2015), January 5-9, 2015. ${ }^{9}$ Mooney, H. P., Brandt, J. B., Lacy, D. S., and Whalen, E. A., “AFC-Enabled Vertical Tail System Integration Study”, NASA/CD-2014-218168, March 2014.

${ }^{10}$ Wohl, C. J., Smith, Jr. J. G., Penner, R. K., Lorenzi, T. M., Lovell, C. S., and Siochi, E. J., "Evaluation of Commercially Available Materials to Mitigate Insect Residue Adhesion on Wing Leading Edge Surfaces," Progress in Organic Coatings, Vol. 76, pp. 42-50, 2013.

${ }^{11}$ Lin, J. C., Whalen, E. A., Eppink, J. L., Siochi, E. J., Alexander, M. G., and Andino, M. Y., "Innovative Flow Control Concepts for Drag Reduction," AIAA Paper No. 2016-0864, 54 $4^{\text {th }}$ AIAA Aerospace Sciences Meeting (SciTech 2016), January 4-8, 2016.

${ }^{12}$ Whalen, E.A., “Active Flow Control Vertical Tail and Insect Accretion and Mitigation Flight Test”, NASA-CR-2016-219005. 